\title{
Rothmund-Thomson syndrome type 1
}

INSERM

\section{Source}

INSERM. (1999). Orphanet: an online rare disease and orphan drug data base. RothmundThomson syndrome type 1. ORPHA:221008

Rothmund-Thomson syndrome type 1 is a subform of Rothmund-Thomson syndrome (RTS; see this term) presenting with a characteristic facial rash (poikiloderma) and frequently associated with short stature, sparse scalp hair, sparse or absent eyelashes and/or eyebrows, and rapidly prog ressive bilateral juvenile cataracts. In contrast to RTS2 (see this term), patients with RTS1 do not appear to have an increased risk of developing cancer. 